

Галина Игоревна Акопова,

заведуюшая залол текущих периодических изданий Российской государственной библиотеки

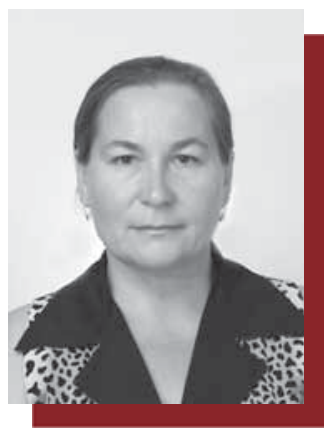

Елена Александровна Крылова, главный библиотекарь зала текуших

периодических изданий

Российской государственной библиотеки

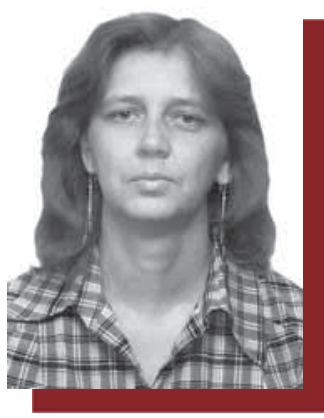

Лариса Сергеевна Рубцова,

главный библиотекарь зала текуших

периодических изданий

Российской государственной библиотеки
Зал текуцих

периодических

изданий

Российской

\section{государственной библиотеки}

(особенности состава, организации

\section{и использования фонда текуиих периодических изданий в РГБ)}

Предлагается краткий исторический экскурс в прошлое зала текущих периодических изданий Российской государственной библиотеки. Расслатриваются особенности работы с отечественной и зарубежной периодикой. Представлена диналика поступлений журналов за последние 30 лет. Отражены результаты изучения использования фонда за разные годы. Приведены статистические данные сравнительного анализа использования печатных и электронных отечественных журналов. Высказаны предложения по улучшению форлирования фондов.

Ключевые слова: Российская государственная библиотека, зал текущих периодических изданий, периодика, отечественные и зарубежные журналы, обязательный экземпляр, электронная версия, профиль комплектования, сравнительный анализ.

Журналы и газеты во многих библиотеках, к сожалению, не пользуются уважением. Наиболее авторитетными и востребованными, а соответственно и более достойными, с точки зрения формирования фондов, в библиотеке являются книги и диссертации. Однако, именно журналы первыми публикуют статьи научных работников, рецензии на издания, позволяют на своих страницах развернуть дискуссию по какой-либо научной проблеме. Публикация в периодике, как правило, предшествует изданию книг и является менее дорогостоящей. Наконец, ни одна научная работа не может обойтись без обзора периодики по теме. В последние годы, учитывая актуальность и оперативность отражения материала, активно развивается, особенно за рубежом, создание полнотекстовых электронных баз, в первую очередь, 
периодических изданий. Все это говорит о том, что последние играют важную роль в развитии современной науки и культуры.

В 2007 г. исполнилось 50 лет со дня создания в Российской государственной библиотеке зала текущих периодических изданий (ЗТПИ). С самого начала зал существует как часть отдела комплектования, и это многое определяет. В отличие от других библиотек, в РГБ периодика (журналы и газеты) поступает отдельными номерами не в основной фонд, а в зал текущих периодических изданий, где хранится и используется несколько лет, а затем уже полными годовыми комплектами передается на постоянное хранение в Центральный основной фонд Библиотеки.

За годы существования зал несколько раз менял свое название - зал текущей периодики (ЗТП), зал периодических изданий (ЗПИ). Но определяющим является все-таки текущая периоди$\kappa a-$ именно свежие журналы и газеты (продолжающиеся издания - поступают сразу в основное хранение РГБ) и это составляет уникальность нашего зала: в других библиотеках залы периодики обычно хранят и выдают периодику за все годы.

Состав фонда ЗТПИ за свою историю претерпевал изменения. Первоначально в зал поступали все выходящие на территории страны отечественные журналы и газеты, получаемые в качестве обязательного экземпляра (в СССР Закон об обязательном экземпляре выполнялся в полном объеме и пробелами могли быть отдельные номера, но не названия, как в настоящее время) и зарубежные журналы (до 13 тыс. названий). Все эти документы собирались и выдавались в ЗТПИ в течение 2 лет. Постепенно, с вводом в действие новых площадей Библиотеки, фонд печатных периодических изданий в ЗТПИ существенно изменился. Так, в конце 1970-х гг. был построен корпус в Химках, где был создан Отдел газет. Туда были переведены поступления обязательного экземпляра всех отечественных газет, а также иностранные газеты. Совсем недавно было открыто здание Центра восточной литературы (ЦВЛ), куда и были перенаправлены поступления журналов на восточных языках. С появлением электронных версий периодики произошло перераспределение денежных средств, и существенно сократился фонд зарубежных печатных периодических изданий.

В настоящее время фонд ЗТПИ насчитывает около 7 тыс. названий отечественных журналов и 1,5 тыс. названий зарубежных журналов за последние три года, около 70 названий наиболее популярных центральных и московских газет за текущий год, получаемых по подписке. С 2000 г. читатели ЗТПИ имеют возможность воспользоваться доступом к более чем 23 тыс. названий отечественных и зарубежных журналов и газет в электронном виде.
Безусловно, электронные версии имеют ряд преимуществ: быстрый поиск, различные возможности сохранения информации и т. д., но обслуживание пользователей ведется в специализированных подразделениях РГБ (например, зале Интернет, зале электронной библиотеки), а основой работы ЗТПИ являются печатные периодические издания, поэтому данная статья касается, в основном, печатной периодики.

Таким образом, цели создания зала оставались неизменными: максимально быстро удовлетворять читательские запросы на наиболее оперативную печатную продукцию - газеты и журналы, формировать полные годовые комплекты, а затем на основе «Профиля комплектования РГБ» отбирать и передавать их для постоянного хранения в Центральный основной фонд РГБ. Остальная часть поступлений (отдельные номера, перепечатки, рекламно-информационные издания, различные каталоги и т. п.) после экспонирования в зале в течение 3 лет исключается из фонда.

Особенности состава, использования и организации фонда текущей периодики в РГБ не раз освещались в периодической печати $[1,2,6]$. Выделение периодических изданий за последние 2 года в оперативную зону позволяет добиться удобства для читателей, с одной стороны, и рациональной обработки периодики - с другой стороны.

На оперативность обслуживания читателей положительно влияет рациональная расстановка периодических изданий в зале. Около 450 названий наиболее востребованных отечественных журналов, получаемых по подписке, центральные отечественные газеты и справочники находятся в открытом доступе зала, для их получения нет необходимости ни писать бланки требований, ни ждать - читатель берет их самостоятельно. Видовой состав фонда открытого доступа ЗТПИ представлен на диаграмме 1. Основу фонда составляют научные журналы, что соответствует статусу Библиотеки.

Основной фонд ЗТПИ составляют издания, расположенные в хранении ЗТПИ, находящемся непосредственно под читальным залом. Они выдаются читателям не позже, чем через 20-30 мин по читательским требованиям, в то время как из основного хранения РГБ заказ выдается через несколько часов или на следующий день.

Методы обработки периодики оттачивались годами. В настоящий момент технология обработки периодических изданий, принятая в ЗТПИ, позволяет предоставлять читателям журналы через $1-3$ дня после поступления в РГБ, а отечественные газеты и журналы, поступающие по подписке, - в течение дня.

Для отражения фонда в ЗТПИ ведутся карточные регистрационные картотеки - алфавитная, географическая и систематическая. Еще од- 
Состав ОД ЗТПИ по типу журналов

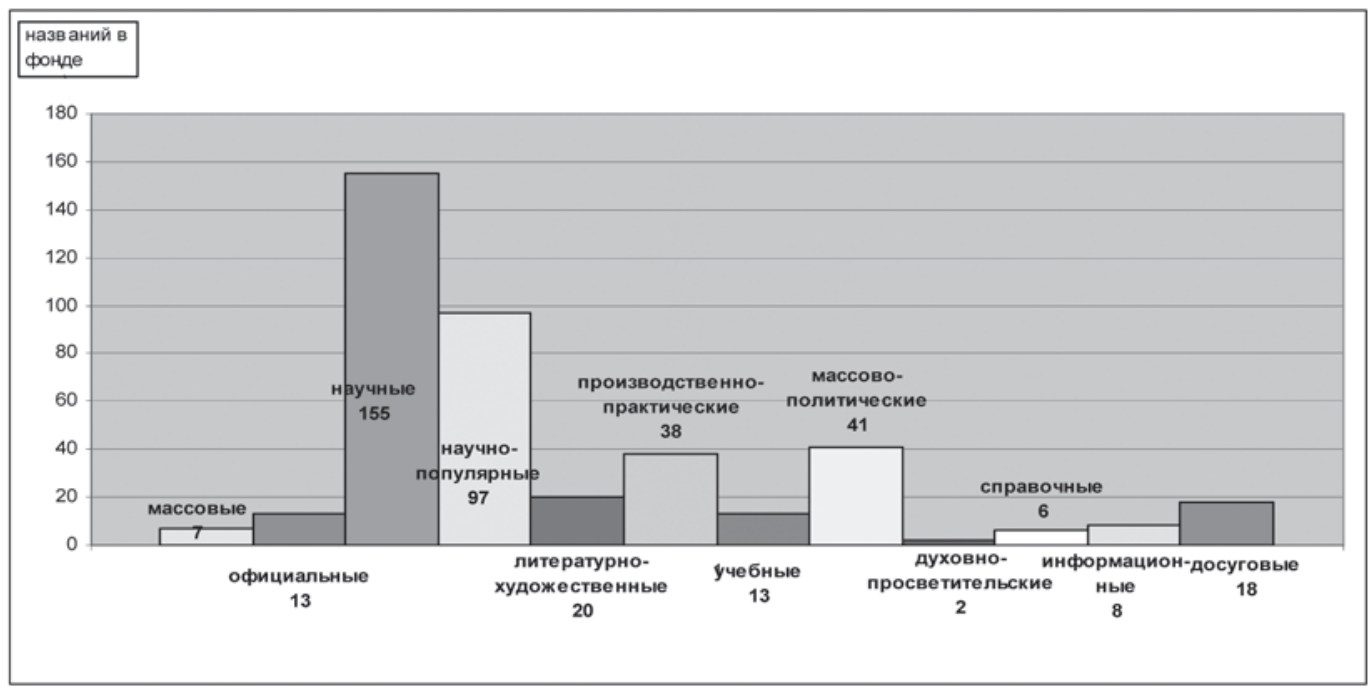

ной уникальной особенностью зала является наличие систематической картотеки периодических изданий. Нигде больше в РГБ систематизация журналов не осуществляется. С 2008 г. отделом комплектования налажена регистрация журналов в электронном каталоге РГБ. Для полноты раскрытия фонда и информирования читателей в зале ведется выставочная работа.

Одна из серьезных проблем, которую не удается решить все эти годы это отсутствие в зале копировальной техники, что, естественно, сказывается на сохранности - вырвать статью проще, чем скопировать.

Помимо обработки изданий и обслуживания читателей, ЗТПИ на основе анкетирования и анализа читательских требований ведет научную работу по изучению состава и использования своего фонда, что способствует наиболее рациональному размещению изданий, совершенствованию комплектования периодики.

По результатам анкетирования читателей выявлено, что в зал приходят в основном те, кто хочет читать именно печатную периодику. Понимая все плюсы электронных изданий, обращаем внимание на то, что пока обслуживание ими платное. Нельзя также лишать права получения информации читателей по возрасту, состоянию здоровья или по невозможности использовать электронные ресурсы. Да и вообще, есть особая магия работы с печатным изданием. Многие постоянные читатели десятилетиями, заказав литературу из хранения, приходят полистать свежие газеты и журналы в наш зал. Треть читателей составляют пенсионеры, следующие по численности - научные работники и студенты. По данным анкетирования читателей проводившегося в 2009-2011 гг., было зафиксировано, что почти $90 \%$ наших читателей - люди с высшим образованием, около $80 \%$ - посещают ЗТПИ ежемесячно, $50 \%-$ с целью ознакомиться с новыми поступлениями отечественных журналов или получить конкретное издание. Более $80 \%$ читателей удовлетворены фондом ЗТПИ.

Работа по изучению читательских требований - весьма трудоемкий процесс. Собираются все требования за определенный период, после ежедневного учета книговыдачи и посещаемости зала они сортируются по названиям. В итоге фиксируется спрос на каждое название в фонде.

Статистический материал, накопленный в зале, не только отражает состав и уровень использования периодики за разные годы, но является своего рода иллюстрацией истории развития нашей страны. В 1960-1970-е гг. - небольшой и стабильный фонд отечественных журналов, огромный спрос на «толстые» литературно-художественные журналы, богатый и разнообразный фонд активно спрашиваемых зарубежных журналов. В середине 1980-х гг., в годы перестройки - значительное возрастание интереса к общественно-политическим отечественным журналам и газетам, публико- 
вавшим в то время сенсационные разоблачающие статьи. В 1990-е гг. - острый дефицит денег на комплектование, резкий спад поступлений зарубежных журналов. В 2000-е гг. - перевод основной части зарубежных журналов в электронный формат. С разрушением Советского Сoюза появляется огромное количество «желтой» прессы, журналов-однодневок, перепечаток, рекламных и гламурных изданий, дублирующих друг друга, разнообразных каталогов товаров и т. п. Нарушение закона об обязательном экземпляре становится правилом, некоторую часть журналов приходится подписывать для докомплектования основного фонда. В то же время Библиотека просто захлебнулась в потоке информационного мусора. Очень остро встала проблема отбора, рекламации, восполнения пробелов, описания и систематизации этих изданий. В этих условиях именно наличие в отделе комплектования такого подразделения, как наш зал, помогало решить многие задачи. Пока журнал находился в фонде зала, выяснялось, что это за издание и стоит ли отправлять его на постоянное хранение.

Анализ использования периодики в ЗТПИ помогает оценить значимость ее научного содержания и провести отбор изданий, делая зал своего рода фильтром для Центрального основного фонда.

Интересна динамика поступления в фонд отечественных журналов за последние 30 лет, представленная на диаграмме 2.

В разные годы акценты изучения фонда варьировались в зависимости от практических потребностей зала и Библиотеки. Так, в 19601980-е гг. регулярно проводилось изучение состава и эффективности использования журналов по различным отраслям знаний, например по биологии, военному делу, юридическим и философским наукам [1, 4, 7].

В 1986 г. были проведены сравнительные анализы состава и использования фонда отечественных журналов по типам изданий и по тематике за 1979, 1982 и 1986 годы. Позже такой же анализ был проведен за 2001, 2005 и 2008 гг. (табл. 1). На основании данной таблицы можно сделать вывод о том, что все разделы фонда ЗТПИ активно использовались. В 2008 г. 7 разделов из 15 , то есть половина, использовались более чем на $50 \%$. В разные годы наиболее активно спрашивались журналы по естественным, физикоматематическим, химическим наукам, технике и общественным наукам.

В 2008 г. были проанализированы возможности повышения использования полнотекстовых электронных версий отечественных и зарубежных журналов. Было выявлено 105 активно спрашиваемых в печатной форме отечественных журналов, доступ к которым имеется также в электронном виде. В открытом доступе зала была размещена дополнительная информация о возможностях получения полных текстов этих журналов в электронном виде. Для иностранного комплектования были подготовлены списки, корректирующие подписной заказ для ЗТПИ.

В 2010 г. ЗТПИ вновь проводил анализ использования фонда за январь-июнь. Было собрано и обработано 20034 читательских требования. Результаты анализа показали, что $60 \%$ отечественного фонда использовалось читателями, $20 \%$ из них - наиболее активно. Неиспользуемая часть фонда - это, в основном, рекламно-информационные, малоинформативные региональные издания.

По результатам изучения использования периодики за 2010 г. в зале был составлен ряд таблиц. Например, выявлены наиболее спрашиваемые отечественные журналы. Отдельно выявлены активно востребованные отечественные журналы, которых не было в открытом доступе зала, по ре-

Диагралма 2

Динамика поступления отечественных журналов в фонд ЗТПИ за 1979-2010 гг.

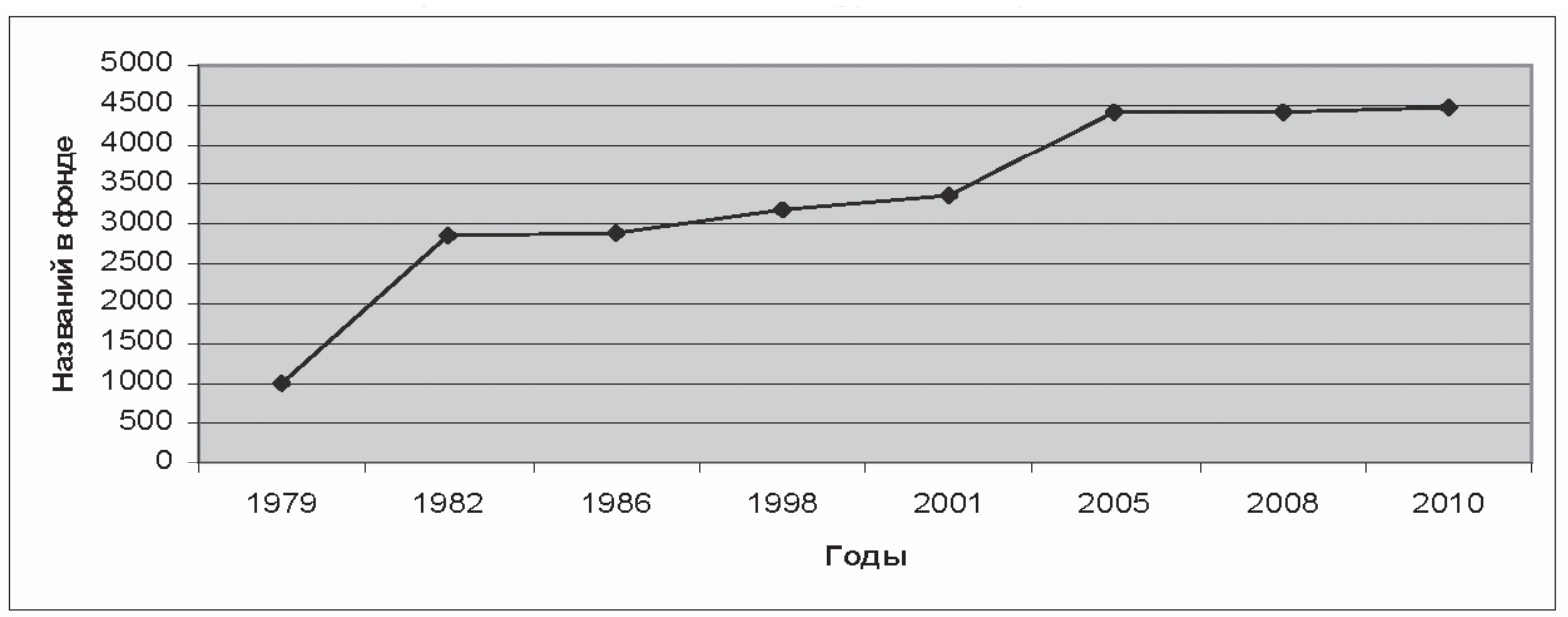


Сравнительный анализ использования фонда отечественных журналов по тематике (в \%)

\begin{tabular}{|l|c|c|c|}
\hline & $\mathbf{2 0 0 1}$ г. & $\mathbf{2 0 0 5}$ г. & $\mathbf{2 0 0 8}$ г. \\
\hline Междисциплинарные и общенаучные знания & 27 & 42 & 61 \\
\hline Естественные науки & 74 & 57 & 53 \\
\hline Физико-математические науки & 38 & 42 & 53 \\
\hline Химические науки & 74 & 49 & 63 \\
\hline Науки о земле & 30 & 44 & 44 \\
\hline Биологические науки & 44 & 36 & 53 \\
\hline Техника & 43 & 59 & 56 \\
\hline Сельское хозяйство & 35 & 46 & 43 \\
\hline Медицина & 44 & 42 & 48 \\
\hline Общественные науки & 60 & 65 & 53 \\
\hline Культура. Наука. Просвещение & 49 & 56 & 49 \\
\hline Филологические науки & 24 & 39 & 38 \\
\hline Искусство & 46 & 60 & 49 \\
\hline Философские науки. Религия & 42 & 67 & 47 \\
\hline Литература универсального содержания & 29 & 56 & 37 \\
\hline
\end{tabular}

Анализ использования некоторых отечественных журналов в печатном и электронном виде

\begin{tabular}{|l|l|c|c|c|c}
\hline \multicolumn{1}{|c|}{$\begin{array}{l}\text { Название } \\
\text { журнала }\end{array}$} & $\begin{array}{l}\text { Спрос в } \\
\text { ЗТПИ } \\
\text { (номера) }\end{array}$ & $\begin{array}{c}\text { Наличие в } \\
\text { ОД ЗТПИ }\end{array}$ & $\begin{array}{c}\text { Спрос с } \\
\text { учем } \\
\text { ОД } \\
\text { (в номе- } \\
\text { рах) }\end{array}$ & $\begin{array}{c}\text { Спрос в пе- } \\
\text { чатном виде } \\
\text { (в 3ТПИ) } \\
\text { (статьи) }\end{array}$ & $\begin{array}{c}\text { Спрос в электронном } \\
\text { виде за последние } \\
\text { годы РГБ в целом) } \\
\text { (статьи) }\end{array}$ \\
\hline $\begin{array}{l}\text { Латинская } \\
\text { Америка }\end{array}$ & 47 & да & 136 & 204 & 169 \\
\hline $\begin{array}{l}\text { Международ- } \\
\text { ная жизнь }\end{array}$ & 84 & да & 243 & 365 & 231 \\
\hline $\begin{array}{l}\text { Новая и новей- } \\
\text { шая история }\end{array}$ & 56 & да & 166 & 249 & 109 \\
\hline $\begin{array}{l}\text { Психологиче- } \\
\text { ский журнал }\end{array}$ & 104 & да & 301 & 452 & 171 \\
\hline $\begin{array}{l}\text { Свободная } \\
\text { мысль }\end{array}$ & 48 & да & 139 & 209 & 116 \\
\hline $\begin{array}{l}\text { Экономика и } \\
\text { математиче- } \\
\text { ские методы }\end{array}$ & 57 & да & 165 & 248 & 169 \\
\hline
\end{tabular}

зультатам анализа 7 из них с 2011 г. представлены на полках открытого доступа. Составлена таблица интенсивности использования отечественных журналов, что позволяет учесть и перераспределить нагрузку на сотрудников зала при работе с фондом. Отдельно проведен анализ использования центральных отечественных газет, поступающих в зал.

Все это позволило скорректировать подписку на 2011 г., к которой специалисты подошли особенно строго: учитывалось наличие электронных версий журнала, наличие журнала в списке ВАК и данные спроса в ЗТПИ. Результаты спроса имели существенное значение при определении изменений экземплярности комплектов, передаваемых в Центральный основной фонд РГБ. Выявлены мало- и неспрашиваемые журналы, которые потом 
Анализ использования литературно-художественных журналов в печатном и электронном виде

\begin{tabular}{|c|c|c|c|c|c|}
\hline $\begin{array}{c}\text { Название } \\
\text { журнала }\end{array}$ & $\begin{array}{l}\text { Спрос в } \\
\text { ЗТПИ } \\
\text { (номера) }\end{array}$ & $\begin{array}{c}\text { Наличие в } \\
\text { ОД ЗТПи }\end{array}$ & $\begin{array}{c}\text { Спрос с } \\
\text { учетом ОД } \\
\text { (номера) }\end{array}$ & $\begin{array}{c}\text { Спрос в печатном } \\
\text { виде (в ЗТПИ) } \\
\text { (статьи) }\end{array}$ & $\begin{array}{c}\text { Спрос в } \\
\text { электронном виде } \\
\text { за последние годы } \\
\text { (в РГБ в целом) } \\
\text { (статьи) }\end{array}$ \\
\hline Звезда & 1 & да & 3 & 5 & 49 \\
\hline $\begin{array}{l}\text { Искусство } \\
\text { кино }\end{array}$ & 1 & да & 3 & 5 & 40 \\
\hline $\begin{array}{l}\text { Молодая } \\
\text { гвардия }\end{array}$ & 1 & да & 3 & 5 & 59 \\
\hline $\begin{array}{l}\text { Наш } \\
\text { современник }\end{array}$ & 7 & да & 20 & 30 & 74 \\
\hline Нева & 0 & да & 0 & 0 & 59 \\
\hline Новый мир & 1 & да & 3 & 5 & 75 \\
\hline
\end{tabular}

Анализ использования наиболее спрашиваемых отечественных журналов в печатном и электронном виде

\begin{tabular}{|c|c|c|c|c|c|}
\hline Название журнала & $\begin{array}{l}\text { Спрос в ЗТПИ } \\
\text { (номера) }\end{array}$ & $\begin{array}{c}\text { Наличие в } \\
\text { ОД ЗТПИ }\end{array}$ & $\begin{array}{c}\text { Спрос с } \\
\text { учетом ОД } \\
\text { (номера) }\end{array}$ & $\begin{array}{c}\text { Спрос в пе- } \\
\text { чатном виде } \\
\text { (в ЗТПИ) (ста- } \\
\text { тьи) }\end{array}$ & $\begin{array}{c}\text { Спрос в электронном виде } \\
\text { за последние годы (в РГБ в } \\
\text { целом) (статьи) }\end{array}$ \\
\hline Азия и Африка сегодня & 90 & да & 261 & 392 & 323 \\
\hline Вопросы философии & 181 & да & 525 & 788 & 281 \\
\hline Вопросы экономики & 123 & да & 357 & 536 & 408 \\
\hline Государство и право & 323 & да & 937 & 1406 & 1678 \\
\hline $\begin{array}{l}\text { Мировая экономика и } \\
\text { международные отно- } \\
\text { шения }\end{array}$ & 171 & да & 496 & 744 & 596 \\
\hline
\end{tabular}

экспонируются на выставках ЗТПИ «Знаете ли Вы эти журналы?»

В тот же период, совместно с отделом хранения и отделом использования удаленных ресурсов, был проведен сравнительный анализ использования печатных и электронных отечественных журналов. Были выделены 56 названий, по которым можно было собрать информацию за 10 лет как по электронным версиям, так и по печатным. Заметим, что это лишь $1 \%$ от всего фонда печатных отечественных журналов, поступающих в ЗТПИ. Интересно, что 22 названия из 56 в печатном виде спрашивались даже больше, чем в электронном (табл. 2). Литературно-художественные журналы, по данным анализа, в электронном виде имеют больший спрос, чем в печатном (табл. 3 ). Показательно, что ряд журналов имеет высокий спрос как в печатном, так и в электронном виде (табл. 4). Эти данные подтверждаются многолетними статистическими показателями ЗТПИ.

Большое внимание уделяется изучению исполь- зования фонда зарубежных журналов. В прежние годы регулярно собиралась и изучалась информация о поступлении и использовании зарубежных журналов по странам. Например, в 1986 г. зал получал журналы из 107 стран мира. В том же году проводилось изучение укомплектованности различных разделов фонда зарубежных журналов и его соответствия информационным потребностям читателей. В настоящее время поступление зарубежных журналов в печатном виде все более и более сокращается, многие из них переходят в электронный формат.

Интересна динамика поступления печатных зарубежных журналов, представленная на диаграмме 3. Иностранная периодика часто поступает в Библиотеку с опозданием. Так, на 1 июля 2010 г. в ЗТПИ за 2010 г. поступило лишь 706 названий зарубежных журналов, на 1 марта 2011 г. за 2010 г. в ЗТПИ поступило 1194 названия.

Изучая использование фонда периодики, зал текущих периодических изданий стремится использовать все имеющиеся возможности для 
максимального удовлетворения запросов пользователей.

При всех плюсах использования журналов в электронном виде хотелось бы заметить, что РГБ как главная государственная библиотека страны должна иметь достойный фонд печатных зарубежных журналов, так как в РГБ читатели зачастую обращаются, когда уже потеряна надежда на получение нужной статьи.

В наши дни, при дефиците времени и денег, переход многих журналов в электронный формат является более дешевым, удобным и практичным. Однако Российская государственная библиотека, кроме функции обслуживания, является хранителем печатных изданий и должна сберечь их для будущих поколений. Генеральный директор РГБ А.И. Вислый подчеркивает: «Мы - национальная библиотека и должны сохранять документы эпохи в их оригиналь-

Диагралмла 3

Динамика поступления зарубежных журналов в фонд ЗПТИ за 1979-2010 гг.

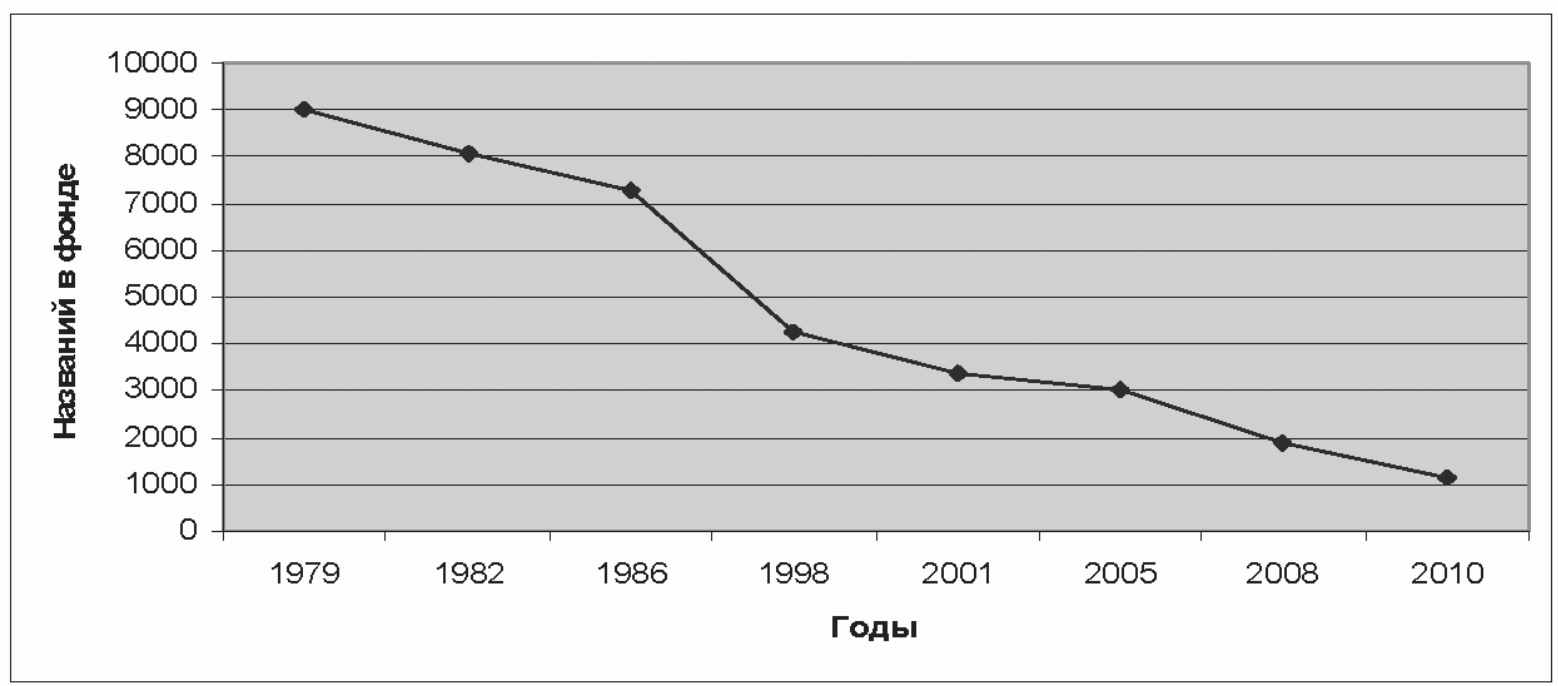

ном виде» [5]. Ни одна библиотека подобного уровня, при всех финансовых проблемах, еще не отказалась полностью от комплектования зарубежной части фонда печатными изданиями.

В мире, где значительная часть периодических изданий переходит в электронный формат, библиотекам вообще, и РГБ в частности, следует искать свое место и новые формы работы с читателями. В 1980-е гг. ГПНТБ России вела сводный каталог зарубежных журналов, поступающих в библиотеки страны. Может быть и сейчас, особенно при дефиците средств у библиотек, имеет смысл создать сводный список зарубежных журналов, получаемых библиотеками России в электронном виде, а также вести подписку на зарубежную периодику, выходящую в печатном и электронном виде, координируя ее с другими библиотеками. Возможно, это позволило бы некоторым библиотекам перераспределить свои средства и направить их на получение новых авторитетных научных журналов.

Таким образом, зал - это активно работающее, мобильное подразделение с динамичным фондом, выполняющее незаметную для непрофессионального взгляда работу, стремящееся улучшить ее для достижения наиболее качественного обслуживания читателей, сохранения национального интеллектуального богатства и развития науки. 


\section{Cписок источников}

1. Брашинская Р.Б. Пути повышения комплектования фондов ГБЛ отечественными журналами / Р.Б. Брашинская, Т.С. Стеценко // Комплектование фондов Государственной библиотеки СССР имени В.И. Ленина отечественными изданиями: Состояние, проблемы, перспективы: сб. науч. тр. / Гос. б-ка СССР им. В.И. Ленина. - М. - 1985. - С. 86-95.

2. Василенко Г. Больше уважения к читателям библиотек / Г. Василенко, В. Середа // Распространение печати. - 1994. - № 4. - С. 18.

3. Вихрева Г.М. Журнальный фонд крупной библиотеки: проблемы качества формирования (на примере ГПНТБ СО РАН) [Электронный ресурс]/ Г.М. Вихрева, О.П. Федотов, Т.С. Ковригина // -
Режим доступа: http://www.rba.ru/or/comitet/12/ mag9/8.pdf

4. Госина Л.И. Оптимизация формирования фонда периодики научной библиотеки на основе изучения читательского спроса / / Науч. и техн. б-ки СССР. 1979. - № 9. - С. $14-20$.

5. Козинова $E$. Рукописи не горят - они оцифровываются (Интервью с А. Вислым) // Аргументы недели. - 2011. - № 1. - С. 14.

6. Краснопольская $К$. Государственная имени Ленина: Зал текущей периодики // Распространение печати. - 1969. - № 10. - С. 5-6.

7. Шулейкин Н.М. Статистическое исследование эффективности использования фондов / Н.М. Шумейкин, Ю.А. Махотенко, Л.С. Новикова / / Науч. и техн. б-ки CCCP. - 1969. — № 9. - C. 17-21.

\section{Анонс}

\section{Новая книга по информационной культурологии}

Колин $K . \kappa$. Информационная культурология: предмет и задачи нового научного направления / К.К. Колин, А.Д. Урсул. - Saarbrucken: LAP LAMBERT Academic Publishing, 2011. — 249 p.

Монография российских ученых, посвященная вопросам философии, теории и методологии

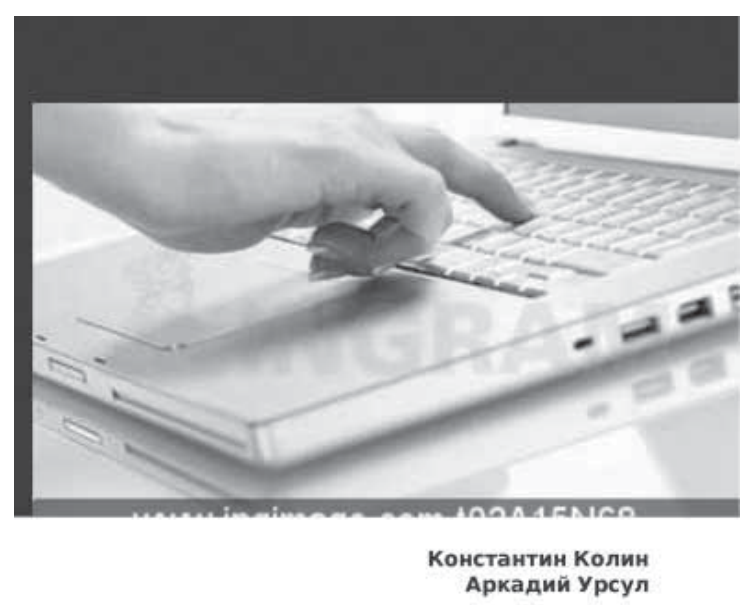

Информационная культурология

Предмет и задачи нового научного направления



информационной культуры, выпущена известным европейским издательством LAP LAMBERT Academic Publishing.

Инфорлационная культурология - новая наука, изучающая феномен культуры и развитие информационной культуры общества на основе концепции информации и информационного подхода. Эта наука сегодня находится в начальной стадии формирования. Однако изучаемые ею проблемы в условиях становления глобального информационного общества являются исключительно актуальными, так как уровень развития информационной культуры сегодня определяет не только качество жизни в той или иной стране, степень ее социально-экономического развития, но также и место этой страны в мировом сообществе, ее национальную безопасность.

В монографии проведен системный анализ состояния, задач и перспектив развития информационной культурологии, ее философских основ и взаимосвязи с проблемами развития информационного общества. Предложены определения понятий «информационная культура» и «электронная культура», рассмотрена структура и содержание предметной области информационной культурологии, а также основные направления ее дальнейшего развития.

Монография включает 17 глав, содержание которых распределено по четырем основным частям:

Часть 1. Философские основания культурь как инфорлационного фенолена

Глава 1. О понятиях информации и культуры 